\title{
The Differences in the Disappearance of Physiological Jaundice in the Newborns on Exclusive Breast-Feeding and Those of Non- Exclusive Breast-Feeding
}

\author{
Gumiarti* \\ *Health Politechnic of Malang, Republic of Indonesia
}

\begin{abstract}
Neonatal Jaundice is a clinical condition characterized by the yellow coloration of the skin and the sclera as the result of the accumulation of uconjugated hyperbilirubin level in the newborns' blood. Jaundice clinically appears in the newborns when the level of bilirubin in the blood ranges from 5-7 mg/dl. Bilirubin in neonate is two to three times higher than the normal adult, because the number of erythrocytes in neonate is higher and the age is shorter. About 50\% of full term and 75\% of preterm newborns suffer from jaundice. The purpose of this study was to determine differences in the disappearance of jaundice in neonates on exclusive breast-feeding and non-exclusive breast-feeding. This study was observational, cross sectional design, while the population was mothers of newborns with physiological jaundice as many as 60 people, 56 of whom were chosen as the samples. Accidental sampling was applied and the measuring instruments used questionnaire and observation sheet. The results showed that the first emergence of physiological jaundice to neonates on exclusive breast-feeding was averagely 2.65 days and averagely 2.70 days to neonates on non-exclusive breast-feeding. The disappearance of physiological jaundice to neonates on exclusive breast-feeding took about 5.77 days and to neonates on non-exclusive breastfeeding took about 7.90 days. The result of the t-test showed that the $p$ value was $0.000(\rho=0,000)$, meaning that the physiological jaundice to neonates on exclusive breast-feeding disappeared faster than neonates on non-exclusive breast-feeding. Thus the mother should be encouraged to breast-feed frequently. The newborns should be exclusively breast-fed with no top feeds, water, or dextrose water, as the protein in breast-feeding can coat the intestinal mucosa, so the liver of the baby will be mature enough to get rid of bilirubin in the bloodstream.
\end{abstract}

Keywords: Jaundice, Exclusive Breast-feeding, non-Exclusive Breast-feeding.

\section{Introduction}

The epidemiological data showed that over 50\% of newborns suffering from jaundice could be detected clinically in the first week of life. In most cases of neonatal jaundice, bilirubin levels were harmless and did not require treatment, most of which did not have the basic causes or called physiological jaundice and would disappear at the end of the first week of life in normal term infants. Other rarely causes reported were hemolysis, septicemia, and metabolic disease (non-physiological jaundice). Neonatal jaundice is a clinical state of the newborn marked with the yellowing of the skin and the sclera of the eye due to accumulation of unconjugated hyperbilirubin. Jaundice clinically will appear in the newborn when the level of bilirubin in the blood ranges $5-7 \mathrm{mg} / \mathrm{dl}$ (Hasan, 2005). Bilirubin in neonates is produced two to three times higher than in normal adults, as the number of erythrocytes in neonates is higher and the age s shorter. Many newborns, especially those weighing less than 2500 grams suffer jaundiced in the first week of life.

The number of jaundice case is about 50\% in full term infants and $75 \%$ in preterm ones. These cases vary from one place to another place influenced by the management of neonates that has a lot of progress lately (Prawiroharjo, 2006). Breast-milk is an emulsion of fat in the solution of proteins, lactose and organic salts secreted by breast (mammary) glands as the primary food for the baby. First milk or colostrums, containing many immunoglobulin $\mathrm{A}(\operatorname{Ig} \mathrm{A})$, is substantially very important to protect the infants against disease. Exclusive breast-feeding is an unequalled way of prividing ideal food for the healthy growth and developments of infants especially until six months of age.According Hasvivin (2013) exclusively breast-fed babies were proned to suffer jaundice by $(2.7 \%)$, while non-exclusively breast-fed babies were a lot higher to suffer jaundice by (32.4\%). The number of jaundice in newborns with normal weight was by (5.4\%) and in newborns with low birth weight experienced by (29.7\%). The impacts when a baby suffered from jaundice and did not receive proper and fast treatment, the baby might have bilirubin encephalopathy, severe complications of neonatal jaundice, sequelae such as cerebral palsy, high notes deafness, paralysis and dental dysplasia which greatly affect quality of life.

To control the bilirubin level, the newborns should be given sufficient amount of liquid and calories as early as possible, because then the motility of the intestinal tract will increase and also cause the introduction of bacteria by which bilirubin was directly altered into urobilin and became unabsorbable. As a 
result, the total serum bilirubin (TSB) could decerease (Bobak, 2004). The provision of adequate liquid can help neonates meet the needs of glucose.The best food for newborns is breast milk because it has great benefits for the neonates in the transitional period. Breast milk contains antibodies, carbohydrates, fats and vitamins. Some of them like beta glucoronidase which functions to break down bilirubin into a soluble form in fat, so the indirect bilirubin will increase and then will be reabsorbed by the intestinal tract.

\section{General Purpose}

To Know the differences of disappearance of physiological jaundice in newborns on exclusive breast-feeding and non-exclusive breast-feeding.

\section{Special Purpose}

1. To identify the first day of the emergence of physiological jaundice in the newborns.

2. To identify the disappearance of physiological jaundice in the newborns.

3. To analyze the differences in the disappearance of jaundice in newborns with exclusive breast-feeding and non-exclusive breast-feeding ones.

\section{Research Benefits}

1. The Theoretical Benefits

To broaden the theory of neonates-midwifery care, particularly in handling the physiological jaundice in the newborn.

2. Practical Benefits

(1) To provide inputs to health care providers (health professionals) for the counseling materials to mothers with infants for the purpose of encouraging them to breast-feed their babies frequently until the age of 6 months even though the baby suffers from physiological jaundice.

(2) To give inputs to other researcher to do further research with different methods and variables in infants with jaundice.

\section{Conceptual Framework}

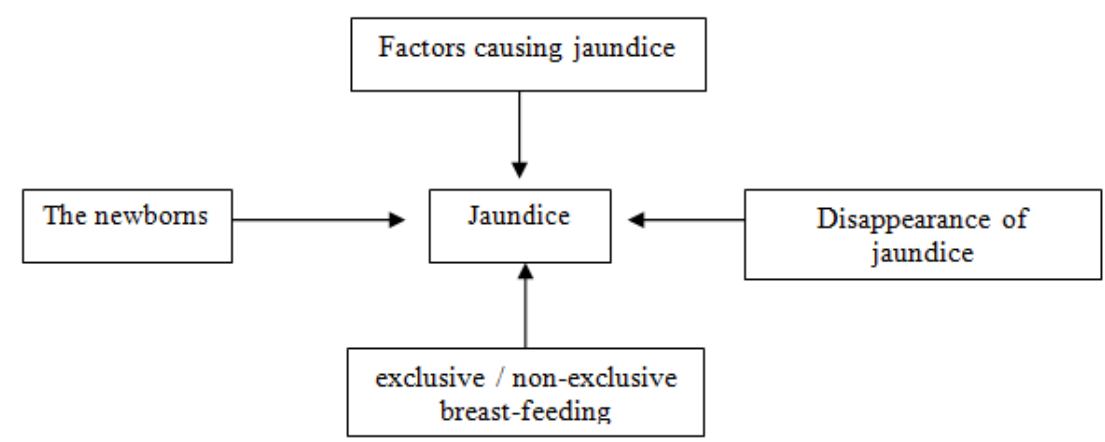

Figure (1) The conceptual framework of the research

\section{Research Hypothesis}

There are some differences in the disappearance of physiological jaundice in the newborns on exclusive breastfeeding and non-exclusive breast-feeding.

\section{Design}

\section{Research Methods}

This research was a comparative study aimed to know the difference of disappearance of physiological jaundice in infants with exclusive breast-feeding and non-exclusive breast-feeding, with cross sectional approach. This research only observed the frequency and characters of the disease and exposure factors in the population at certain point of time (Nursalam, 2008).

\section{Population and Sample}

The population of this study was mothers of newborns with physiological jaundice in Independent Practice of Midwifery (BPM) in Patrang Sub-district, Jember district, East Java, Republic of Indonesia. The total population was 60 people, 56 of whom met the criteria to be the samples based on the Slovin formula (Nursalam, 2008).

\section{Sampling Technique}

To obtain the data, accidental sampling by which the available subjects were simply entered into the study without any attempt at randomization was opted. 


\section{Research Variables and Operational Definitions}

(1) Physiological jaundice emerges on the second day or the third day and has no basis in pathology or do not have the potential to be pathological jaundice. The symptomps are as follows: a) appear in the second and third day, b) the level of indirect bilirubin does not exceed $10 \mathrm{mg} \%$ in term neonates, c) the increasing speed of bilirubin levels does not exceed 5\% per day, d) direct bilirubin does not exceed $1 \mathrm{mg} \%$, e) Jaundice will disappear in the first 10 days, f) no symptoms related to pathological conditions.

(2) Exclusive breast-feeding means that the infants receive only breast milk from birth until the age of 0-6 months. No other liquids or solids are given such as formula milk, juice, tea water, honey and not even water.

(3) Non-exclusive breast-feeding means that the infants receive both at the same time breast milk and additional food like liquids or solids from birth until the age of 0-6 months.

\section{Data Analysis}

In bivariate analysis, independent t-test therefore was used to determine whether differences arose in the disappearance of physiological jaundice in the newborn on exclusive breast-feeding and that of non-exclusive breast-feeding.

\section{Result}

Table (1) Frequency Distribution of the Emergence of Physiological Jaundice in the newborns

\begin{tabular}{|l|l|l|l|l|l|}
\hline No. & Newborns on Exclusive Breast-feeding & $\mathbf{x}$ & $\%$ & Mean & SD \\
\hline 1. & Day 2 & 9 & 34,6 & 9 & 34,6 \\
\hline 2. & Day 3 & 17 & 65,4 & 17 & 65,4 \\
\hline & Newborns on Non-exclusive Breast-feeding & & & & \\
\hline 1. & Day 2 & 9 & 30 & 9 & 30 \\
\hline 2. & Day 3 & 21 & 70 & 21 & 70 \\
\hline
\end{tabular}

Table (1) indicated that in the newborns on exclusive breast-feeding, the physiological jaundice appeared in day 2 as $34,6 \%$ and day 3 as $65,4 \%$, while newborns on non-exclusive breast-feeding the physiological jaundice appeared in day 2 as $30 \%$ and day 3 as $70 \%$.On average, on day 1 the emergence of physiological jaundice of newborns on exclusive breast-feeding was 2,65 days with deviation standard of 0,485 , while for newborns on Non-exclusive Breast-feeding was 2.70 days with deviation standard of 0,466 .

Table (2) Frequency Distribution of the Disappearance of Physiological Jaundice in the newborns

\begin{tabular}{|c|c|c|c|c|c|}
\hline No. & Newborns on Exclusive Breast-feeding & $\mathbf{x}$ & $\%$ & Mean & SD \\
\hline 1. & Day 5 & 12 & 46,1 & \multirow{3}{*}{5,77} & \multirow{3}{*}{0,051} \\
\hline 2. & Day 6 & 10 & 38,4 & & \\
\hline 3. & Day 7 & 3 & 11,5 & & \\
\hline & Newborns on Non-exclusive Breast-feeding & & & & \\
\hline 1. & Day 5 & 1 & 3,3 & \multirow{6}{*}{7,90} & \multirow{6}{*}{1,155} \\
\hline 2. & Day6 & 1 & 3,3 & & \\
\hline 3. & Day 7 & 9 & 30 & & \\
\hline 4. & Day 8 & 11 & 36,7 & & \\
\hline 5. & Day 9 & 5 & 16,7 & & \\
\hline 6. & Day 10 & 3 & 10 & & \\
\hline
\end{tabular}

Table (2) indicated that in the newborns on exclusive breast-feeding physiological jaundice disappeared on day 5 as $46,1 \%$, on day 6 as $38,4 \%$, on day 7 as $11,5 \%$, on day 9 as $3,8 \%$, while for newborns on non-exclusive Breast-feeding physiological jaundice disappeared on day 5 as $3,3 \%$, on day 6 as $3,3 \%$, on day 7 as $30 \%$, on day 8 as $36,7 \%$, on day 9 as $16,7 \%$, on day 10 as $10 \%$.

Table (3) The analysis of difference of physiological jaundice disappearance in the newborns on exclusive breast-feeding and those of non-exclusive Breast-feeding

\begin{tabular}{|l|l|l|l|l|l|l|}
\hline Breast Milk Provision & Mean & SD & SE & P Value & 95\% CI & N \\
\hline Exclusive & 5,77 & & 0,187 & 0,000 & -2.703 & 26 \\
Non-exclusive & 7,90 & 0,051 & 0,211 & & -1.558 & 30 \\
& & 1,155 & & & & \\
\hline
\end{tabular}

Table (3) indicated that physiological jaundice disappearance in the newborns on exclusive breast-feeding on average was 5,77 days, while for newborns on non-exclusive breast-feeding 7, 90 days. Independent t-test result showed $\mathrm{p}=0,000$ which means that difference arose on physiological jaundice disappearance between newborns on exclusive breast-feeding and that of non-exclusive breast-feeding. Of newborns on exclusive breast-feeding physiological jaundice disappeared more quickly than that of nonexclusive breast-feeding. Based on $95 \%$ of interval confidence value, it is believed that through exclusive breast-feeding, physiological jaundice in the newborns will likely disappear faster. 


\title{
IV. Discussion
}

\author{
Time of emergence of physiological jaundice in the newborns on exclusive breast-feeding and those of \\ non-exclusive breast-feeding
}

Research result indicated that the first emergence of physiological jaundice in the newborns on exclusive breast-feeding was 2,65 days on average, while for those of non-exclusive breast-feeding physiological jaundice appeared at 2,70 days on average. The result was in line with the theory of Risa et al (2006) that physiological jaundice in the newborn was yellowish color on sclera and skin caused by hyperbilirubin. At the initial stage, physiological jaundice appears in sclera (the white part of eyes) and face, then spreads out in the cephalocaudal area (from the upper and lower part of the body) through chest, belly and extrimity. Of the newborns, physiolgical jaundice does not normally visible on sclera as they generally cannot open eyes. A large number of neonates experience indirect high level of bilirubin on the first day of life both physiological and pathological jaundice. This happened due to physiologic process on neonates. The process took place owing to high level of erythrocytes in neonates in which the lifespan of erythrocytes on neonates is shorter than that of adults around 80-90 days and also due to undeveloped functions of liver. The high level of bilirubin happened on day 2 or 3 and was on the peak on day 5-7, physiological jaundice appeared on day 2 or 3 of the newborns.

\section{The Disappearance of Physiological jaundice in the newborns on exclusive breast-feeding and those of non- exclusive breast-feeding}

The research result indicated that the disappearance of physiological jaundice in newborns on exclusive breast-feeding was 5,77 days on average and those of non-exclusive breast-feeding the disappearance of physiological jaundice was 7,90 days on average. Of newborns on exclusive breast-feeding bilirubin silted beneath the skin especially on sclera and face on day 2 and day 3 will likely disappear when the newborn was exclusively breast-fed, direct bilirubin on the intestinal-tract will be tied up by food inside it and will be released as sterkobilin together with faeces. Though newborns on exclusive breast-feeding may experience jaundice, when usually breast-fed since birth date, they will obtain intake from cholostrum release, so that direct bilirubin will be tied up by food and released through urine faeses. Baby with physiological Jaundice who has yet consumed enough breast-feeding, no specific medication, even not fresh water, sugar and formula milk; only breast-feeding actions needed more regularly, as baby is in need of it, at least eight times a day by monitoring breast-milk sufficiency through urine observation (6-7 times a day) and faeces (3-4 times a day).Thus, direct bilirubin will be tied up and released through urine and fesses until jaundice disappeared. The newborns with physiological jaundice and on exclusive breast-feeding will likely undergo Jaundice disappearance on day 9. This is due to the decrease of jaundice level to Kremer 2 (Behrman, 2000).Whereas, in the newborns with physiological jaundice and on non-exclusive breast-feeding, their intestinal mucosa is not coated with protein from cholostrum. This condition enables bilirubin to be easily reabsorbed by direct intestine bilirubin and will be altered to be indirect bilirubin which will at the same time be reabsorbed into blood to improve enterohepatic circulation. Baby with jaundice and on non-exclusive breast-feeding but still consume other intakes, the breast-milk intake will be hampered or not optimal. As the result direct bilirubin bond was not either optimal or will enable to prolonge jaundice disappearnce (Hegar,2008).

\section{The difference of physiological jaundice disappearance between newborns on exclusive breast-feeding and those of non-exclusive breast-feeding}

From t-test result, the duration of jaundice disappearance of newborns on exclusive breast-feeding and those of non-exclusive breast-feeding showed value of $p=0,000$ which means the physiological jaundice disappeared more quickly to baby on exclusive breast-feeding than that of non-exclusive breast-feeding.

This is because after the delivery, the newborns directly undergo early breast-feeding initiation (IMD) or provided with cholostrum which binds direct bilirubin that will be released through faeces or urine. Furthermore, milk protein will coat intestinal mucosa so that direct bilirubin is not reabsorbed into bloodstream and will be changed into indirect bilirubin. In the newborns with physiological jaundice and on non-exclusive breastfeeding, although tend to obtain cholostrum, the addditional milk will hamper the process of breast milk production as a result not all direct bilirubin bound by food will be released through faeses and urine. The disappearance of physiological jaundice can be due to sun exposure (Etika, 2006).

\section{Conclusion}

\section{Conclusion and Suggestion}

The research concluded that the difference of physiological jaundice disappearance experienced by Newborns on exclusive breast-feeding and those of non-exclusive breast-feeding shows up with the following points: 
1. On day 1, the appearance of physiological jaundice of babies on exclusive breast-feeding occured more quickly than those of non-exclusive breast-feeding.

2. The disappearance of physiological jaundice of babies on exclusive breast-feeding occured more quickly than those of non-exclusive breast-feeding.

\section{Suggestion}

Based on the research result, some suggestions need to be taken into consideration which might be useful for those of medical practitioners as follows:

1. Mothers of babies with physiologican jaundice are hoped to keep exclusive breast-feeding. Normally, only a little cholostrumruns, but with regular actions, breast milk will be produced faster and better in quantity. Breast milk mixed with additional components will likely hamper the production of good breast milk.

2. Paramedics are hoped to provide prospective mothers and women with enough information on this issue especially the benefit of exclusive breast-feeding. This is particularly important when their babies suffer from physiological jaundice.

\section{References}

[1]. Behrman, et al., (2000), Ilmu Kesehatan Anak Nelson, Jakarta, EGC

[2]. Bobak et al., (2006), Buku Ajar Keperawatan Maternitas, Edisi 4, Jakarta, EGC

[3]. Etika, (2006), Hyperbilirubinemia in Neonatus, Surabaya: Fakultas Kedokteran Universitas Airlangga

[4]. Hasvivin, (2013), Pemberian ASI, Riwayat Asfiksia dan BBL dengan kejadian ikterus neonatorum, Penelitian.

[5]. Hasan, R, (2005), Inkompatibilitas ABO dan Ikterus pada Bayi baru Lahir in Buku Kuliah Ilmu Kesehatan Anak, Jakarta, Salemba Medika

[6]. Hegar, e. Al., (2008), Bedah ASI, IDAI cabang DKI Jakarta; Jakarta

[7]. Nursalam, (2008), Metodologi Penelitian, Jakarta, Salemba Medika

[8]. Risa, E., et al., (2006), Hiperbilirubinemia pada Neonatus, Divisi Neonatologi bagian Ilmu Kesehatan Anak, FK Unair/RSU Dr.Soetomo Surabaya, Available from, http://www.pediatrik.com.

[9]. Prawiriharjo, (2009), Buku Acuan Nasional Pelayanan Maternal dan Neonatal, Jakarta, Yayasan Bina Pustaka. 